\title{
Física para as graduações tecnológicas em construção de edifícios: um olhar histórico (1961-1974)
}

Fábio Aparecido da Costa

Polonia Altoé Fusinato

\section{Resumo}

Nesta pesquisa, buscou-se uma contribuição à educação profissional e tecnológica ao investigar a origem do componente curricular Física para os cursos superiores de tecnologia em construção de edifícios do Brasil. A ausência dos conteúdos curriculares na legislação específica e a atualidade do debate sobre a formação profissional e tecnológica revelam a importância dessa temática. 0 objetivo é apresentar reflexões sobre a origem do componente curricular Física para esses cursos no período compreendido entre 1961 e 1974. A pesquisa histórica com abordagem documental, as legislações e entrevistas com os indivíduos envolvidos no processo de criação e início de expansão desses cursos compuseram as fontes desta pesquisa, e com vistas a apreender a função educacional do componente curricular, a planificação curricular compôs a categoria de análise. Os resultados apontam que a nomenclatura atribuída ao componente curricular e seus conteúdos de instrução não condizem com as finalidades prescritas na legislação.

Palavras-chave: ensino de Física, formação profissional, tecnologia em construção de edifícios.

\section{Abstract}

Physics for graduation in the technology for the building of premises: a historical view (1961-1974)

The origin of the introduction of Physics in the curriculum of higher technological courses in building premises in Brazil is investigated as a contribution towards professional and technological education. The importance of the theme may be shown by a lack of curriculum contents in specific legislation and the updating of discussions on the professional and technological formation. The paper discusses the origin of the discipline Physics for these courses, between 1961 and 1974. Historical research in documents, legislation and interviews with people involved in the process of the establishment and expansion of these courses are the sources of current investigation. Curricular planning composed the analysis category to understand the educational function of the curricular component. Results show that the nomenclature given to the curricular component and its instruction contents do not comply with the aims in the legislation.

Keywords: the teaching of Physics; professional formation; technology in building construction. 


\section{Introdução}

O presente artigo sustenta-se nos resultados de pesquisa desenvolvida para a elaboração da dissertação $A$ identidade da Física nas graduações tecnológicas em construção de edifícios, defendida em 2013 no Programa de Pós-Graduação em Educação para a Ciência e a Matemática da Universidade Estadual de Maringá. Essa pesquisa teve como objetivos identificar e analisar se os cursos superiores de tecnologia em construção de edifícios apresentam componente curricular Física conforme previsto no Parecer no 29, de 03 de dezembro de 2002, exarado pelo Conselho Pleno do Conselho Nacional de Educação, sendo esse o Documento Definidor das Diretrizes Curriculares Nacionais Gerais para a Educação Profissional e Tecnológica, doravante denominado Documento Oficial.

A pertinência da temática deve-se à atualidade do debate relativo à formação profissional e tecnológica. As discussões acerca dos modelos de formação profissional, polivalente e politécnico, estão cada vez mais em pauta considerando os documentos expedidos pelo Ministério da Educação que visam à regulamentação e à adequação do processo de formação profissional nos dois níveis da educação escolar instituídos pela Lei de Diretrizes e Bases da Educação Nacional de 1996.

De acordo com Zabalza (2007, p. 38), para se referir aos processos vinculados à aprendizagem conceitos mais tradicionais são utilizados, tais como educação, ensino, instrumentação, treinamento, entre outros. No entanto, o termo formação é o mais apropriado para os estudos pedagógicos por se tratar de um processo que perpassa a vida dos indivíduos, extinguindo a dicotomia entre profissão e vida, desde que

\section{"[...] tomado não só como uma actividade de aprendizagem situada em tempos e espaços específicos, mas também como acção vital de construção de si próprio. Ninguém se forma no vazio. Formar-se supõe troca, experiência, interacções sociais, aprendizagens, um sem fim de relações. Ter acesso ao modo como cada pessoa se forma é ter em conta a singularidade da sua história e sobretudo o modo singular como age, reage e interage com os seus contextos (MOITA, 2000, p. 114-115)."}

Nóvoa (2000, p.25) declara que a formação não pode ser construída por meio da acumulação de cursos, de conhecimentos e/ou de técnicas, mas somente através de um trabalho de reflexividade crítica e de (re)construção permanente, o que reporta

$$
\begin{aligned}
& \text { "[...] a um processo de preparação, às vezes genérica, às vezes especializada, } \\
& \text { com a intenção de capacitar os indivíduos para a realização de certas } \\
& \text { atividades. [...] Sob essa perspectiva, qualquer atividade universitária deveria } \\
& \text { estar atingindo três aspectos sobre os quais se projeta o sentido da formação: } \\
& \text { o desenvolvimento pessoal, o desenvolvimento de conhecimentos e }
\end{aligned}
$$

252 DOI: Em andamento.

R. Bras. de Ensino de C\&T 
competências específicas e uma visão mais ampla do mercado de trabalho a fim de agir nele com mais autonomia (ZABALZA, 2007, p. 45)."

Um dos focos do debate sobre a formação profissional e tecnológica se concentra no processo de organização curricular constante nos documentos: Parâmetros Curriculares Nacionais para o Nível Básico e Diretrizes Curriculares Nacionais para o Nível Superior. Nesses documentos são apresentadas orientações referentes à forma de organização dos cursos e dos conteúdos curriculares que devem constar em cada nível da educação escolar. No entanto, para as graduações tecnológicas, que correspondem a cursos de nível superior na área de tecnologia, em suas Diretrizes Curriculares Nacionais constam somente orientações gerais para a organização e o funcionamento dos cursos, estando ausentes os conteúdos curriculares para cada um deles.

Zabalza (2003, p. 7-11, tradução nossa) explica que no processo de planificação curricular quatro tipos de conteúdos formativos devem ser considerados: os culturais gerais; os gerais e inespecíficos; os disciplinares gerais; e os disciplinares especializados. Os dois primeiros se destinam à formação geral, e os outros dois, à formação profissional.

No Documento Oficial é justificado que tanto a interpretação quanto a alocação dos conteúdos de ensino que se julgarem necessários para a formação do profissional tecnólogo são de competência das Instituições de Ensino Superior mantenedoras dos cursos. Esse motivo levounos a investigar como os conteúdos formativos disciplinares gerais e específicos, exclusivos para o componente curricular Física, foram interpretados e alocados pelas instituições educativas mantenedoras dessa modalidade de cursos, uma vez que a legislação brasileira não aborda especificamente esse assunto, tratando-o apenas de forma geral.

Compartilhamos a defesa de Shulman (1986) ao afirmar que para o pleno desenvolvimento de sua disciplina é necessário que o professor conheça o currículo, os programas de ensino, o material a ser selecionado visando às articulações horizontais e verticais do conteúdo programático, a história da evolução do conteúdo a ser ensinado, entre outros aspectos.

Nosso objetivo neste artigo é apresentar reflexões sobre a origem da disciplina de Física para os cursos superiores de tecnologia em construção de edifícios no período compreendido entre a primeira Lei de Diretrizes e Bases da Educação Nacional, promulgada em 1961, e o término do Projeto 19, do Plano Setorial de Educação e Cultura, em 1974, que tratava da implantação gradativa dos cursos de curta duração no país. Essa delimitação se torna importante porque após o término do Projeto 19, outros desses cursos superiores foram implantados no país e o componente curricular em análise adquiriu nomenclaturas e finalidades educacionais distintas. Para cumprir essa proposta, utilizamos como categoria de análise os conteúdos formativos, em uma pesquisa histórica com abordagem documental. 
Esse objetivo se pauta na assertiva de Ribeiro (2011, p. 820) de que voltar às origens de uma disciplina é um importante exercício para um balanço de suas permanências e transformações no cenário educacional brasileiro. O aprofundamento de pesquisas atinente à história da disciplina escolar traz subsídios para a história da educação em nosso país.

Por se tratar de uma pesquisa histórica com abordagem documental, é necessário o estabelecimento de um referencial teórico-metodológico para sua concretização, assunto da próxima seção.

\section{Referencial teórico-metodológico}

A pesquisa histórica com abordagem documental assume a nova história como aporte teórico indispensável para sua realização. É a partir dela que se abrem novas possibilidades para a análise de fontes documentais, possibilitando ao pesquisador um modelo de análise conectado à sua base teórica- filosófica constituinte.

O pressuposto de análise nesse tipo de pesquisa é a compreensão dos fenômenos históricos por meio dos acontecimentos passados. Nesse sentido, Buffa (2002, p. 26-28) defende que os princípios teórico-metodológicos devem considerar: as relações entre trabalho $e$ educação; o debate entre visões gerais e descrições do singular; e a história de maneira não apenas factual nem apenas descritiva, mas também interpretativa. Isso implica no estabelecimento de uma categoria de análise, isto é, em "[...] um conceito que nos permite dar uma 'arrumação', um 'arranjo' no campo que se quer investigar' (BUFFA, 2005, p. 41).

$\mathrm{Na}$ pesquisa que deu origem a este artigo, elegeu-se a planificação curricular, especificamente os conteúdos formativos como categoria de análise visando a apreender a função educacional do componente curricular Física no processo de criação e início de expansão dos cursos superiores de tecnologia em construção de edifícios no país.

As fontes são consideradas o ponto de partida de uma pesquisa e correspondem a "[...] todo o conjunto de documentos registrados em arquivos, museus, bibliotecas e ambientes de documentação e todo e qualquer documento a serviço da pesquisa em educação" (ANDRADE, 2011, p. 26).

Arnaut de Toledo e Gimenez (2009, p. 111) esclarecem que as fontes podem ser primárias ou secundárias. As fontes primárias nos remetem diretamente à própria problematização da pesquisa e, em geral, são documentos produzidos no período pesquisado, sejam eles originais depositados em arquivos ou digitalizados (ou copiados). Por sua vez, as fontes secundárias nos transmitem os fatos de maneira indireta e nem sempre correspondem aos documentos produzidos no período pesquisado. Elas fornecem informações, datas e fatos, que nos permitem compreender conceitos e a configuração do referencial teórico metodológico da análise. Os 
autores complementam que as fontes secundárias são compostas por dicionários especializados, enciclopédias, dados estatísticos, legislações e outras fontes de referência, como os "relatos feitos por pessoas que não vivenciaram diretamente os episódios relatados e que se baseiam em outras fontes orais ou documentais".

Em nossa pesquisa, consideramos fontes primárias a palestra de Nelson Alves Vianna e as entrevistas com os indivíduos envolvidos no processo de criação dos cursos e do componente curricular Física. As fontes secundárias corresponderam aos documentos governamentais correspondências, relatórios, legislação vigente etc. Utilizamos, ainda, outros documentos como literatura de apoio.

Na escritura deste artigo, apoiamo-nos em autores como: Chervel (1990), principalmente no conceito de disciplina escolar, em sua relação com os conteúdos de ensino e com as finalidades educativas; Zabalza (2003; 2007), que discorre sobre o processo de planificação curricular e os conteúdos formativos; Alvarenga (1976), Ramos (1979), Rothen (2005) e Soares (1979), que apresentam as funções das disciplinas com base na legislação brasileira vigente à sua época; Hewitt (2002), Rocha (1946), Sociedade Brasileira de Física (1987) e Young e Freedman (2008), que tratam da importância da Física para os cursos de engenharia e tecnologia; Coll et al. (2004), que auxiliam na compreensão do significado atribuído para uma disciplina aplicada; Coll, Solé e Onrubia (1999), que definem o significado e as dimensões de uma disciplina ponte; Alvetti (1999), Ostermann e Ricci (2002) e Terrazzan (1994), que abordam o ensino de Física Moderna e Contemporânea; Motoyama (1995), que expõe as entrevistas com Ricardo (1995), Tolle (1995), Watanabe (1995), entre outros envolvidos no processo de criação e expansão desses cursos no país. A obra de Motoyama (1995) também é por nós utilizada porque transcreve a palestra de Vianna (1995).

\section{A pesquisa}

A história da disciplina de Física para os cursos superiores de tecnologia do Brasil tem sua origem em 1894, com a implantação de cursos superiores de curta duração e a respectiva emissão de certificados correspondentes ao técnico de nível superior em diversas instituições de ensino do país, dentre elas a Escola Politécnica de São Paulo e a Universidade do Paraná.

Até 1928, encontramos relatos de cursos superiores de curta duração destinados à formação dos seguintes profissionais técnicos de nível superior: mecânicos, condutores de trabalhos, agrimensores, maquinistas, contadores, topógrafos e químicos, cursos com duração de dois anos. Após esse período, foram extintos e/ou transformados em cursos de graduação plena.

A discussão referente a cursos superiores de curta duração para atender campos específicos do mercado de trabalho permaneceu esquecida por longo período. O tema foi retomado durante os debates para a aprovação da Lei no 4.024, de 20 de dezembro de 1961, que 
pela primeira vez fixava as Diretrizes e Bases da Educação Nacional. Em seu Artigo 104, foi estabelecida a permissão para a organização de cursos ou escolas experimentais, com currículos, métodos e períodos escolares próprios.

No Documento Oficial, consta que, ancorado no Artigo 104 da Lei № 4.024/1961 e no Parecer no 280/1962, emitido pelo Conselho Federal de Educação, foi proposta, em 1962, a criação de cursos de engenharia de operação de curta duração. No entanto, o conteúdo desse Parecer foi omitido, dificultando o entendimento sobre o assunto.

$\mathrm{Na}$ literatura específica da área educacional não houve a preocupação em revelar o conteúdo do Parecer no 280/1962. A explicação para a criação dos cursos de engenharia de operação e/ou de outros cursos superiores de curta duração passou a ser atribuída, então, a uma possível divisão do Ensino Superior em dois ciclos, mencionada no Parecer no 58 exarado em 1962 pelo Conselho Federal de Educação, cujo relator foi Valnir Chagas.

A impressão deixada na literatura, devido à ausência do conteúdo do Parecer no 280/1962, e a respectiva substituição de seu conteúdo pela menção da divisão cíclica contida no Parecer no 58/1962 é de que os cursos de engenharia de operação representariam o ciclo básico para a formação mais longa em engenharia plena; no entanto, essa afirmação não é verdadeira.

Chervel (1990, p. 191-192) propala que quando se deseja estudar as finalidades do ensino, a primeira documentação que se abre imediatamente diante do historiador é a série de textos oficiais programáticos, que fixam os planos de estudos e/ou programas. Entretanto, o autor adverte que não se deve basear unicamente nos textos oficiais e que é essencial dialogar com os pesquisadores do assunto.

O documento que se abre para essa exploração é o Parecer no 280, de 19 de outubro de 1962, emitido pelo Conselho Federal de Educação, que estabelecia pela primeira vez os currículos mínimos dos cursos de engenharia no Brasil. Desse Parecer destacamos que cada um dos currículos é constituído pelo conjunto de matérias necessário a uma adequada formação cultural e profissional, por isso as matérias de cada currículo foram divididas em dois grupos: matérias básicas e matérias de formação profissional.

O componente curricular básico de Física foi designado por Física Geral nos currículos mínimos para a formação dos engenheiros civis, mecânicos, eletricistas, metalurgistas, de minas, navais e químicos. No currículo mínimo para formação de agrônomos, o componente curricular recebeu a denominação Física. As nomenclaturas elencadas para os componentes curriculares são essenciais para a compreensão das prescrições legislativas sobre os cursos superiores de curta duração a partir de 1963.

Nos Projetos de Resoluções que se seguiram àquele Parecer, a cada uma das modalidades de engenharia elencadas os componentes curriculares foram agrupados em dois ciclos de estudo: 
(i) Ciclo Básico, que compreendia as disciplinas básicas; e (ii) Ciclo de Formação Profissional, que compreendia as disciplinas de formação profissional.

A divisão do currículo em dois grupos de componentes curriculares é explicada por Zabalza (2003, p. 39, tradução nossa) ao afirmar que a estrutura curricular de um curso pode ser dividida em etapas, nas quais os estudos de primeira fase ou ciclo de preparação são curtos, com uma preparação eminentemente disciplinar, para propiciar uma ampla formação de base, servindo de fundamentação para as fases posteriores, chamadas fases de formação profissional.

No Parecer no 280/1962, justificou-se que devido ao desenvolvimento industrial do país, as escolas poderiam propor, ao Conselho Federal de Educação, cursos orientados inteiramente para certos domínios da Tecnologia, desde que fosse mantida a parte básica. Isso porque o "núcleo básico de qualquer proposta curricular deve estar naquilo que constitui a essência da formação a que é orientado" (ZABALZA, 2003, p. 43-44, tradução nossa), ou seja, as disciplinas que compõem o campo da educação básica em cada profissão devem desempenhar um papel principal.

Desde a emissão daquele Parecer até a Reforma Educacional de 1968, "[...] o único objetivo das disciplinas introdutórias parecia ser o de oferecer aos estudantes, o preparo necessário a estudos ulteriores" (ALVARENGA, 1976, p. 217), incluindo aqui as disciplinas de Física ministradas nos anos iniciais dos cursos superiores do Brasil. A autora utiliza a terminologia disciplinas introdutórias com o mesmo sentido atribuído para matérias básicas no Parecer no 280/1962.

Diversos autores (HEWITT, 2002; ROCHA, 1946; SOCIEDADE BRASILEIRA DE FÍSICA, 1987; YOUNG E FREEDMAN, 2008) afirmam que cientistas e engenheiros de todas as áreas utilizam os conceitos da física, uma vez que eles fundamentam essas ciências mais complicadas e constituem a base de toda engenharia e tecnologia, haja vista que, antes de projetar um dispositivo prático mais eficiente, todo engenheiro deve entender os princípios básicos da física. É por essa e outras razões que a física não é simplesmente um ramo das ciências da natureza, sendo considerada ciência fundamental, e a compreensão da ciência deve-se iniciar com uma compreensão da física, visando a possibilitar à compreensão de aspectos complexos da natureza, criar sistemas, dispositivos e materiais artificiais, bem como contribuir para o progresso tecnológico.

Ressaltamos que a física constitui um conteúdo formativo fundamental para engenheiros e tecnólogos, pois a formação deste último profissional deve ter "[...] foco no domínio e na aplicação de conhecimentos científicos e tecnológicos" (BRASIL, 2002, p. 17). Para tanto, se faz necessária uma sólida formação em física.

O texto do Parecer no 280/1962 faz menção à possibilidade de o currículo ser desenvolvido em prazo mais breve, por se acreditar que o mercado de trabalho necessitava de dois tipos de engenheiros: um comum, apto para executar a rotina das operações industriais; e 
outro de alto nível, responsável por promover o progresso e o desenvolvimento industrial. Os engenheiros comuns posteriormente foram denominados engenheiros de operação, e os engenheiros de alto nível foram chamados de engenheiros plenos e tiveram seu currículo mantido com prazo mais longo.

O plano de criação da nova modalidade de engenharia foi aprovado pelo Conselho Federal de Educação, em fevereiro de 1963, ao ser exarado o Parecer no 60, no qual foi estabelecido que nenhum dos componentes curriculares, concluídos em curso de engenharia de operação, poderia ser utilizado para complementar os estudos para a obtenção do título de engenheiro pleno.

Brandão (2009, p. 57) atesta que o engenheiro pleno continuaria formado com as atribuições criadoras de pesquisa, de desenvolvimento e da elaboração de projetos. O novo curso de engenharia, denominado engenharia de operação, teria sua formação em curso com duração de três anos, reduzindo os gastos com a formação por ser mais curto que os cursos de formação plena.

Nesse mesmo período, foi desencadeada em São Paulo a ideia de criação de cursos superiores de curta duração análogos aos que existiam em outros países, s como na Inglaterra (Colleges of Advanced Tecnology), Itália (Istituti), Estados Unidos da América (Junior Colleges), França (Institutes Universitaires de Techonogie) e Japão (Tanki Daigaku).

Peterossi (1980, p.34-35) assinala que a ideia foi apresentada no Parecer no 44/1963, subscrito pelo conselheiro Paulo Ernesto Tolle e expedido pela Câmara de Estudos Superiores do Conselho Estadual de Educação de São Paulo, no qual constava que "as primeiras justificativas para a criação de uma nova modalidade de profissionais". Os "estudantes que não revelassem bons dotes", ocupariam funções de "auxiliares de engenheiros" na indústria. Essa ideia não frutificou e foi retomada, também sem êxito, em 1965, quando o professor Octávio Gaspar de Souza Ricardo enviou ao conselheiro Paulo Ernesto Tolle uma carta dos Estados Unidos da América relatando a formação de profissionais, acima do nível técnico, em cursos de aproximadamente dois anos de duração.

Em âmbito nacional, a fixação do currículo mínimo do curso de engenharia de operação para três anos, cuja formação seria acentuada nas disciplinas de conteúdo profissionalizante e a titulação atribuída seria a de engenheiros tecnológicos, foi estabelecida por meio do Parecer $\mathrm{n}$ ㅇ 25, de 04 de fevereiro de 1965, do Conselho Federal de Educação que dispôs sobre o funcionamento dos cursos de engenharia de operação em estabelecimentos de ensino de engenharia.

No referido Parecer, os cursos de engenharia de operação deveriam propiciar uma formação profissional tecnológica, isto é, com conteúdo profissionalizante e voltado mais para a prática do que para a teoria. Os cursos de engenharia plena, por sua vez, deveriam propiciar uma 
formação profissional científica, possuindo preparação científica muito mais ampla. A visão atribuída à época para considerar um curso como tecnológico era de que este possuísse conteúdos profissionalizantes voltados mais para a prática do que para a teoria.

Na Portaria no 36, de 09 de fevereiro de 1965, exarada pelo Ministro da Educação e Cultura Flávio Suplicy de Lacerda, homologando o currículo mínimo estabelecido para os cursos de engenheiro de operação, consta que deveria ser contemplada o ensino de Física e concedido grande importância ao ensino da Física Experimental e suas aplicações tecnológicas.

Chamamos a atenção em relação à prescrição para a nomenclatura da disciplina Física. Essa nomenclatura deveria ser oficializada em todos os cursos de engenharia de operação com o fito de diferenciá-la da nomenclatura adotada para a formação plena e para o cumprimento do Parecer no 60/1963, sobre a impossibilidade de validação das disciplinas cumpridas nos cursos de engenharia de operação para a complementação de estudos em engenharia plena.

Destacamos que os cursos de engenharia de operação não foram divididos em dois ciclos de estudo. A configuração curricular dos cursos se assemelhava à dos cursos de arquitetura e urbanismo; no entanto havia distinção das denominações das disciplinas de Física. Para os cursos de arquitetura e urbanismo, a nomenclatura atribuída foi Física Aplicada, e para os cursos de engenharia de operação, Física.

O currículo mínimo dos cursos de arquitetura e urbanismo foi estabelecido no Parecer no 336, de 17 de novembro de 1962, instituindo que algumas matérias deveriam ser orientadas em sentido instrumental com vistas à aplicação da prática das Composições e dos Planejamentos, dentre as quais se encontravam: (i) as matérias técnico-científicas de aplicação direta, como Cálculo, Mecânica, Resistência dos Materiais, Estabilidade das Construções e Sistemas Estruturais; (ii) Técnica da Construção, Materiais de Construção, Física Aplicada e Higiene e Saneamento, que compunham os sistemas e métodos de construção, conjuntamente com as instalações técnicas complementares; e (iii) os meios de representação e expressão, designados por Desenho, Plástica, Geometria Descritiva e Perspectiva, e Topografia.

Notamos que a Física Aplicada não era considerada uma disciplina técnico-científica de aplicação direta, mas integrante dos sistemas e métodos de construção, bem como de instalações técnicas complementares. Rocha (1946, p. 24-25) pontua que, por via de regra, o profissional da construção civil não recebe do físico as leis elaboradas de modo a aplicá-las diretamente à resolução dos seus problemas. O autor complementa que:

\section{" [...] [é] necessária uma série de desenvolvimentos exigidos pela necessidade} da sua extensão, mais ou menos legítima, a casos particulares que, não interessando ao físico, sejam importantes nas aplicações. $O$ engenheiro tem [...] que vencer bolsas de resistência deixadas pela frente de avanço do conhecimento das leis naturais. Assim se constituem as ciências técnicas ou 
aplicadas que, como a Resistência dos Materiais, a Hidráulica, a Aerodinâmica Aplicada, a Termodinâmica Aplicada e a [...] [Eletricidade Aplicada], são a pormenorização de ramos da Física que interessam especialmente ̀̀ Engenharia."

Para compreendermos o significado atribuído ao componente curricular Física Aplicada, recorremos aos escritos de Coll et al. (2004, p. 22), segundo os quais:

\section{"[...] [nas] disciplinas aplicadas [...] existem ramos separados com teorias aplicadas que são tão básicas como as teorias existentes nas disciplinas de origem, mas que são formuladas em um nível inferior de generalidades e têm mais relevância direta e mais aplicabilidade aos problemas práticos em seus respectivos campos."}

Lança $(2008$, p.2) e a Sociedade Brasileira de Física (1987, p. 22) asseveram que a Física Aplicada não deve ser tida como uma disciplina estanque, isto é, uma disciplina isolada, fechada em si mesma, autônoma e autossuficiente. Ela deve ser tomada como uma disciplina cujos conhecimentos são aprofundados e aplicados em outras disciplinas, somando competências de mais de um setor de atividade científica, porque a atuação conjunta determinará uma área associada e/ou interdisciplinar, como ocorreu, por exemplo, quando a Física se associou à Medicina, originando a Física-Médica.

Observamos que, nesse caso, não existe uma concepção unilateral, ou seja, o estudo da Física pela sua comunidade interna, pois a disciplina não deve ser isolada, não deve ser autônoma e autossuficiente, mas deve se associar a outras disciplinas. Brasil (2001) assinala que embora se utilize prioritariamente o instrumental (teórico e/ ou experimental) da Física, o físico atuará de "forma conjunta e harmônica com especialistas de outras áreas, tais como químicos, médicos, matemáticos, biólogos, engenheiros, administradores" etc. Ademais, para aprofundar um conhecimento é necessário estudar um fenômeno e/ou fato de interesse, e esse estudo deverá ser colocado em prática e/ou empregado em outra área de conhecimento, de modo a gerar conhecimentos interdisciplinares. Os conhecimentos gerados na área interdisciplinar já não pertencerão somente à Física, por isso é imprescindível uma formação sólida em física, considerando que esses novos conhecimentos determinam uma ponte entre as áreas associadas e/ou uma disciplina ponte.

Uma disciplina associada ou disciplina ponte terá natureza aplicada, como descrito por Coll, Solé e Onrubia (1999, p. 56-57), porque possui como característica a utilização do conhecimento em determinada área para a resolução dos problemas de outra área e, obrigatoriamente, comporta três dimensões: (a) teórica ou explicativa, cuja finalidade é "contribuir para a elaboração de uma teoria que permita compreender e explicar melhor os processos"; (b) projetiva ou tecnológica, cuja finalidade é "auxiliar na elaboração de 
procedimentos, estratégias e modelos de planejamento e intervenção que permitam orientá-los em uma determinada direção"; e (c) prática, cuja finalidade é "coadjuvar para a instauração de práticas mais eficientes, mais satisfatórias e mais enriquecedoras".

Ao retomar a prescrição contida na Portaria no 36/1965 para conceder-se grande importância ao ensino da Física Experimental e suas aplicações tecnológicas, é possível notar que a disciplina de Física para os cursos de engenharia de operação apresenta nuances de Física Aplicada. Contudo, salientamos que a ministração de uma disciplina de Física dividida em aulas teóricas e atividades experimentais não indica que ela está sendo aplicada em outra área do conhecimento, uma vez que a outra área pode não corresponder a um campo de aplicação direta dos instrumentos da Física; ademais, essa divisão está preconizada pela própria natureza da disciplina de Física.

Zabalza (2003, p. 9, tradução nossa) sustenta que alguns conteúdos formativos são diferenciados entre disciplinas de fundamentação (geralmente teóricas e gerais) e disciplinas de aplicação (geralmente práticas e ligadas a âmbitos profissionais especializados). As disciplinas de Física e Física Aplicada, respectivamente, para os cursos de engenharia de operação e de arquitetura e urbanismo, correspondiam a conteúdos formativos disciplinares distintos. Para o curso de engenharia de operação, tratava-se de Física Geral - conteúdo formativo geral e específico, ao passo que para o curso de arquitetura e urbanismo a física ensinada correspondia a um conteúdo formativo especializado, específico daquela formação profissional.

Em 1967, quando Roberto Costa de Abreu Sodré assumiu o Governo do Estado de São Paulo, o professor Tolle indicou Octávio Gaspar de Souza Ricardo para compor o Conselho Estadual de Educação, e a ideia de criação de cursos superiores para formação de tecnólogos ganhou corpo e consistência.

Naquele momento histórico, os cursos de engenharia de operação estavam em pleno funcionamento, visando a atender às demandas da indústria, e somente dela, principalmente da indústria automobilística. No entanto, o Governo do Estado de São Paulo desejava a criação de cursos superiores de curta duração que pudessem atender às demandas locais e regionais, em todos os setores profissionais nos quais houvesse utilização de tecnologia.

Octávio Gaspar de Souza Ricardo, em discurso proferido durante a V Reunião Conjunta dos Conselhos de Educação e no relatório do grupo de trabalho da reforma universitária de 1968, defendeu veementemente o pioneirismo na elaboração teórica dos cursos que se pretendiam criar e argumentou que o engenheiro operacional e o técnico de nível superior (tecnólogo) se envolvem em atividades na engenharia para resolver problemas específicos já resolvidos nos livros e nos manuais e/ou tomar decisões quanto à melhor maneira de executar uma determinada tarefa, tais como projetar uma viga ou uma engrenagem, construir uma torre em treliça, entre outras.

R. B. E. C. T., vol 8, núm. 3, mai-ago.2015 ISSN - 1982-873X

DOI: Em andamento. 
Mesmo colocando o engenheiro operacional e técnico de nível superior em uma única área, a do fazer, o professor Ricardo frisou que existe distinção entre os dois profissionais. Inicialmente, asseverou que "o terceiro ano do curso de engenharia operacional já conferia um grau de especialização superior, em 50\%, ao técnico preparado em apenas dois anos" (BRASIL, 1974, p. 11).

A aproximação entre os dois profissionais é mantida na versão histórica dos cursos apresentada pelo Ministério da Educação no Documento Oficial; todavia os cursos de engenharia de operação, ao serem extintos em 1976, foram transformados em cursos de engenharia industrial e não em cursos superiores de tecnologia.

Naquela época, a pressão para que o Governo do Estado de São Paulo criasse escolas de nível superior era muito forte. Por isso, por meio da Resolução no 2.001, de 15 de janeiro de 1968, Sodré constituiu um grupo de trabalho para estudar a viabilidade da implantação gradativa de uma rede de cursos superiores com duração de dois e três anos, cujo relatório foi entregue ao governador em 19 de fevereiro de 1968. Esse foi o passo decisivo para a criação dos cursos superiores de tecnologia, tanto no Estado de São Paulo como na própria cidade de São Paulo.

Tolle (1995, p. 102-103) relata que mediante o Decreto no 49327, de 21 de fevereiro de 1968, instaurou-se o Grupo de Trabalho para a Promoção do Ensino Tecnológico no Estado de São Paulo com o intuito de incentivar os municípios a organizarem escolas para oferecer cursos de tecnologia. Esse grupo de trabalho não foi muito bem sucedido. Criou-se apenas pela iniciativa privada - a Faculdade de Tecnologia de Bauru.

A Fundação Educacional de Bauru, mantenedora da Faculdade de Engenharia dessa cidade, solicitou ao Conselho Estadual de Educação do Estado de São Paulo, em 1968, autorização para o funcionamento da Escola Superior de Tecnologia e da Faculdade de Ciências. Tanto a apreciação quanto a autorização integram o Parecer no 25/1968 e a Resolução no 30/1968, ambos relatados pelo conselheiro Paulo Nathanael Pereira de Souza.

Há também o Ato no 309, de 26 de novembro de 1968, expedido pelo Secretário de Estado dos Negócios da Educação, do Estado de São Paulo, que homologou a Resolução no 30, de 19 de novembro de 1968, aprovada em sessão plena pelo Conselho Estadual de Educação, autorizando a instalação da Escola Superior de Tecnologia da Fundação Educacional de Bauru, com dois cursos de Tecnologia: o de Construção Civil (Movimentos de Terra) e o de Sistema Elétricos (Distribuição de Energia).

O período compreendido entre a criação da Faculdade de Tecnologia de Bauru e o início das atividades letivas de seus cursos superiores de curta duração foi marcado, em âmbito nacional, pela Reforma Educacional promulgada pela Lei no 5.540, de 28 de novembro de 1968, na qual se oficializou a divisão cíclica do Ensino Superior, composta de um ciclo básico, 
fundamentado "[...] na concepção de que a precoce especialização do estudante não seria salutar para a formação científica e cultural deles" (ROTHEN, 2005, p. 108).

No Artigo 5o do Decreto-Lei № 464, de 11 de fevereiro de 1969, estabeleceram-se normas complementares à Lei no 5.540/1968, dispondo que nas instituições de ensino superior que mantivessem diversas modalidades de habilitação,

"os estudos profissionais de graduação serão precedidos de um primeiro ciclo, comum a todos os cursos ou a grupos de cursos afins, com as seguintes funções: a) recuperação de insuficiências evidenciadas, pelo concurso vestibular, na formação de alunos; b) orientação para escolha da carreira; c) realização de estudos básicos para ciclos ulteriores (BRASIL, 1969)."

Soares (1979, p. 49) esclarece que esses objetivos correspondiam aos objetivos gerais de cada disciplina que compunha o primeiro ciclo. Toda e qualquer disciplina de Física que se encontrasse no primeiro ciclo passou então a ser denominada, comumente, por Física Básica e tinha os mesmos objetivos gerais citados no Decreto-Lei no 464/1969. Nesse texto, a Física Básica era representada pelas disciplinas de Física Geral para o ciclo básico das engenharias e de Física para a agronomia. Para os componentes curriculares Física e Física Aplicada, para os cursos de engenharia operacional e arquitetura e urbanismo, respectivamente, os objetivos gerais foram mantidos. Para o curso de engenharia operacional, a manutenção do objetivo se deu pela impossibilidade de validação das disciplinas cumpridas nos cursos de engenharia de operação para a complementação de estudos em engenharia plena, contida no Parecer no 60/1963. No caso do curso de arquitetura e urbanismo, a manutenção do objetivo ocorreu por se tratar de um componente curricular específico daquela formação profissional.

Ramos (1979, p. 52) assevera que o ciclo básico compreendia grandes áreas de conhecimento e se destinava a fundamentar uma variedade de carreiras da mesma área, o que Ihe atribuía caráter de generalidade. Por isso, era propedêutico, e não profissional. A autora adverte que possuir caráter de generalidade não implica, necessariamente, que no Ensino Superior se deva oferecer cultura ou educação geral, embora possa e deva realizar-se durante os estudos universitários, principal missão do Ensino Básico, uma vez que educação geral é a "educação que coloca o indivíduo em contato com as principais linhas de conhecimento válidas para um determinado período histórico ou para uma dada cultura".

Ao investigar os trabalhos apresentados em simpósios de ensino de Física que seguiram após a Reforma de 1968, Soares $(1979$, p. 51) pontua que as diversas propostas de objetivos para a Física Básica podem ser assim sintetizadas:

"o ciclo básico de Física deve não só fornecer uma sólida formação em Física, incluindo Física moderna, como também deve orientar e estimular nos alunos 
um processo de conhecimento mais amplo, ou seja, identificá-lo com métodos e processos científicos e sua integração crítica com a realidade."

Em estudos realizados anos mais tarde, Ostermann e Ricci (2002, p. 177) identificaram que toda a Física desenvolvida do século XX em diante estava excluída dos currículos escolares do Ensino Básico, por isso a inserção da Física Moderna e Contemporânea era preconizada para complementar "lacunas do ensino de $2^{\circ}$ grau e oferecer estudos básicos para ciclos ulteriores, quer venham a ser, para cada aluno, profissionais ou acadêmicos" (RAMOS, 1979, p. 52). Ademais, ao se tratar de um processo de formação é preciso considerar que:

"[...] [a] discussão sobre o papel da ciência física na sociedade não pode ser realizada sem o conhecimento da produção científica da atualidade. A formação do indivíduo deve equilibrar-se entre a aquisição de conhecimentos especializados, decorrentes da sua profissão ou dos interesses particulares, $e$ conhecimentos mais universais, mais amplos e abstratos, imprescindiveis para a sua participação na vida societária e exercício da cidadania (ALVETTI, 1999, p. 21).“

Terrazzan (1994, p. 210-211) sublinha que "devemos lembrar a impossibilidade de se vivenciar e participar plenamente do mundo tecnológico atual sem um mínimo de conhecimentos básicos dos desenvolvimentos mais recentes da Física". Essa advertência é compartilhada por Martí (1976, p. 85), como podemos observar na afirmação de que é "criminoso o divórcio entre a Educação recebida em uma época e a época".

A preocupação com o ensino de Física Moderna e Contemporânea, à época, indicava que o componente curricular Física possuía tanto conteúdos formativos culturais gerais quanto disciplinares gerais, indicando tratar-se de um componente curricular básico e/ou geral. O que diferenciaria, em termos de ensino de física, a formação dos engenheiros plenos da formação dos engenheiros de operação era o fato de que os primeiros estudariam a Física Moderna e Contemporânea e os outros não.

Em 09 de abril de 1969, pela Resolução no 2.277, uma comissão foi instaurada com o intuito de elaborar o projeto de criação e o plano de instalação e funcionamento de um instituto tecnológico educacional do Estado de São Paulo. Este receberia o nome de Instituto de Ensino Técnico Paula Souza e se destinaria a proporcionar habilitações intermediárias de grau superior em campos prioritários da tecnologia, assim como a formar docentes para o ensino técnico. Porém, tanto o nome do instituto como suas finalidades foram alteradas pelo Decreto Lei, sem número, de 06 de outubro de 1969, pelo então Governador do Estado de São Paulo, que criou como entidade autárquica o Centro Estadual de Educação Tecnológica de São Paulo visando articular e desenvolver a educação tecnológica nos graus de ensino médio e superior. 
Por meio do Decreto de 24 de outubro de 1969, Sodré designou os membros do Conselho Deliberativo que dirigiriam os destinos da entidade, sendo uma de suas atribuições "propor a estruturação dos cursos a serem ministrados, levando em conta sua adequação às necessidades do mercado de trabalho" (MOTOYAMA, 1995, p. 470).

O Conselho Deliberativo decidiu que, inicialmente, no Centro Estadual de Educação Tecnológica de São Paulo seriam ofertados dois cursos superiores de curta duração: (a) o de Construções Civis, nas modalidades de Construções de Edifícios, Construção de Obras Hidráulicas e Movimento de Terra e Pavimentação; e (b) o de Mecânica, nas modalidades de Oficinas, Desenhista e Projetista (VIANNA, 1995, p. 201).

Octavio Gaspar de Souza Ricardo afirma ter participado ativamente na construção dos currículos daqueles cursos. O autor revela que definir qual elenco seria compatível, ao mesmo tempo, com a duração de dois anos, com carga horária aceitável, e com o objetivo de dar realmente uma formação profissional foi o maior problema enfrentado, de modo que se adotou a seguinte solução:

\section{"[...] [a] matemática e a física seriam apenas as do 2 o grau, seria suficiente. As disciplinas receberam os nomes de Métodos de Cálculo e Física Aplicada, para ressaltar o fato e evitar confusões e ilusões nos alunos. Simples recordação do que deveria ter sido aprendido no $2^{\circ}$ grau. Ter-se-ia evitado o problema de reprovações em massa (RICARDO, 1995, p. 122-123)."}

Há aqui a gênese do componente curricular Física para os cursos superiores de tecnologia, que recebeu o nome Física Aplicada, tendo características de "simples recordação do que deveria ter sido aprendido no 20 grau" (RICARDO, 1995, p. 123). No entanto, essa característica não é a de um conteúdo formativo disciplinar especializado, mas sim de um conteúdo formativo disciplinar geral. Frisamos que esse componente curricular se assemelhava ao do curso de engenharia operacional.

A expressão "ressaltar o fato e evitar confusões e ilusões nos alunos" (RICARDO, 1995, p. 123) se refere à prescrição contida no Parecer no 60/1963. Essa prescrição foi reforçada no processo de expansão dos cursos e integra o relatório do Projeto no 19 do Plano Setorial de Educação e Cultura para o período de 1972/1974, do qual destacamos que a própria denominação das disciplinas para os cursos superiores de tecnologia, mesmo quando apresentassem conteúdo equivalente ao de outro curso superior tradicional, deveria ser diferente, porque "tudo deveria ser feito para que o curso de tecnólogo fosse apresentado ao candidato como algo especial e terminal, que o conduziria à imediata inserção no mercado de trabalho" (BRASIL, 2002, p. 8). Em hipótese alguma os cursos corresponderiam a "simples degrau ou estágio de curso de maior duração" (BRASIL, 1974, p. 54). 
Chervel (1990, p. 191) defende que a função das disciplinas escolares "consiste em cada caso em colocar um conteúdo de instrução a serviço de uma finalidade educativa". A finalidade educativa com base na legislação vigente à época era a de complementação de lacunas e instrumentação para os estudos em ciclos ulteriores, uma vez que o conteúdo de ensino deveria ser análogo ao do Ensino Básico e não o de aplicação dos conhecimentos especializados na área da construção de edifícios. Com essas características, o componente curricular não poderia ser denominado Física Aplicada.

No Conselho Federal de Educação, o conselheiro Tarcísio Damy de Souza Santos foi o relator do Parecer no 278, de 09 de abril de 1970, que aprovou o plano para o curso técnico de nível superior do Centro Estadual de Educação Tecnológica de São Paulo. Desse Parecer, salientamos que a Física Aplicada seria uma disciplina comum aos cursos de Construções Civis e o ensino seria desenvolvido em aulas teóricas e aulas práticas, e as aulas práticas representariam cerca de metade do total da carga horária, assegurando maior ênfase na formação prática dos alunos. Esse plano de cursos citava apenas o nome das disciplinas, não suas ementas.

Embora no Parecer fossem mencionadas aulas práticas, não houve menção explícita para o componente curricular Física Aplicada. Mesmo as aulas práticas correspondendo à metade do total das aulas, os fatos de o componente curricular Física Aplicada ser comum aos cursos de construção civil e de o conteúdo de ensino corresponder ao preenchimento de lacunas do Ensino Básico corroboram o conteúdo formativo como disciplinar geral e/ou de fundamentação, bem como indicam a possibilidade de consideração de um ciclo básico para esses cursos.

Watanabe (1995, p. 329-331) afirma ter sido um dos primeiros professores de Física Aplicada daquela entidade e declara que em "física I, o conteúdo era a física geral, com enfoque em estática. Em física II, a dinâmica, com evidência em roto-translação". Ele acredita existir um erro que persiste até hoje, pois na "área da construção civil há uma predominância do estudo do equilíbrio, sendo a estática fundamental, e a física I se presta muito bem para essa área"; no entanto, para os cursos dessa área eram ministradas as disciplinas de física I e II. Em física II, estuda-se "toda a parte de dinâmica, sendo de interesse do curso de mecânica, para o qual não é oferecida".

A terminologia Física I e Física II foi utilizada para indicar que o componente curricular Física Aplicada era ministrado em dois períodos letivos consecutivos, sendo destinados para isso os dois primeiros períodos desses cursos. As declarações de Watanabe reforçam a assertiva de que o componente curricular era de formação geral, bem como discriminam, de maneira geral, os conteúdos de ensino. Contudo, essas declarações apontam uma nova visão sobre o componente curricular Física Aplicada, a de que o nome lhe fora atribuído por se tratar de recortes do conteúdo de ensino de Física que interessavam diretamente àqueles cursos tecnológicos. 
No Parecer no 1.063, de 04 de julho de 1973, que aprovou o plano para o curso técnico de nível superior em Mecânica - Modalidade: Oficinas e Manutenção, para ser ministrado pelo Instituto de Tecnologia da Universidade Federal do Espírito Santo, o Conselheiro Tarcísio Damy de Souza Santos destacou que, em linhas gerais, o currículo proposto seguia o do Centro Estadual de Educação Tecnológica de São Paulo, cujo nome havia sido alterado para Centro Estadual de Educação Tecnológica Paula Souza; contudo, a nomenclatura de algumas disciplinas deveria ser adequada, com base no enfoque a ser dado "às disciplinas formativas do curso (Matemática, Física, Química)", pois era daquelas disciplinas, que se deviam "visar às aplicações, e assim servir de instrumento ou de ferramenta, para o estudo das disciplinas profissionalizantes" (BRASIL, 1974, p. 54).

Essa citação corrobora os objetivos postos para o ciclo básico e para os conteúdos formativos disciplinares gerais, indicando que os componentes curriculares de Física serviam de base para estudos ulteriores. Deles se visariam às aplicações nos ciclos profissionalizantes. No entanto, não se configurava a hipótese de constituição de um ciclo básico para os próprios cursos de tecnologia.

Souza Santos sugeriu que o nome Física Experimental fosse substituído por Física Geral Experimental e que se mantivesse o nome Física Aplicada como disciplina distinta; argumentando que para "[...] se ajuizar sobre a organização dessas disciplinas e sobre as aulas que devem objetivar ensinamento experimental (laboratórios, aulas de oficina, trabalhos em usinas-piloto, projetos, exercícios), é necessário que sejam [...] [separadas] as aulas expositivas das práticas" (BRASIL, 1974, p. 55).

A argumentação de Souza Santos aponta uma incoerência entre os objetivos postos e o conteúdo de ensino. Não era o fato de possuir aulas práticas que determinava o caráter aplicativo de um componente curricular. A separação entre aulas teóricas e práticas de um mesmo componente curricular apenas indicava a necessidade de adequação da nomenclatura, que deveria evidenciar o caráter misto a ela atribuído, por isso o autor sugeriu o nome Física Geral Experimental.

Ao analisar a ementa, Souza Santos declarou que a nomenclatura Física Aplicada era incorreta, pois não se tratava do ensino de aplicações da Física, mas do estudo de tópicos daquela disciplina que interessavam diretamente à natureza do curso. Nas palavras do Conselheiro, era "desnecessária a designação de Química Analítica Aplicada, [...] [uma vez] [...] que é da natureza da disciplina sua orientação para aplicações. Aqui, também, o programa atenderia especificamente aos objetivos do curso" (BRASIL, 1974, p. 67). Contudo, quando a disciplina não apresentasse essa natureza aplicativa, sua nomenclatura deveria ser adequada às finalidades educativas. 
Embora o Conselheiro Souza Santos não se referisse especificamente ao curso superior de tecnologia em construção de edifícios, sua defesa para a correta denominação de componentes curriculares continua válida, porque a nomenclatura de uma disciplina deve ser condizente com “[...] a forma de organização do conteúdo do ensino em cada grau, nível ou série, compreendendo aquilo sobre o qual versa o ensino, ou em torno do que se organiza o processo de ensinoaprendizagem" (SAVIANI, 2010, p. 115-116), considerando que as disciplinas escolares são os "modos de transmissão cultural que se dirigem aos alunos" (CHERVEL, 1990, p. 186) e precisam, portanto, apresentar similaridades entre as finalidades prescritas e os resultados concretos por ela produzidos.

Mesmo os currículos sofrendo alterações no decorrer dos anos, é possível notarmos claramente que o nome Física Aplicada atribuído à disciplina de Física para os cursos superiores de tecnologia em construção de edifícios vincula-se a três fatos: (1) o nível do conteúdo a ser ministrado possuía características de preenchimento de lacunas; (2) o conteúdo de ensino correspondia a tópicos que interessavam diretamente à área a ser ministrado; e (3) a não utilização de nomenclatura análoga à dos cursos de engenharia plena.

O terceiro fator, presente no Relatório do Projeto no 19 do Plano Setorial de Educação e Cultura para o período de 1972/1974, induz à premissa de que os componentes curriculares deveriam possuir caráter diferenciado dos cursos de graduação tradicionais, e quando isso não ocorresse, pelo menos o nome deveria ser diferenciado. No entanto, essa recomendação, ao longo dos anos, propagou equívocos quanto à nomenclatura de um componente curricular, uma vez que suas finalidades não condiziam com a natureza da nomenclatura que lhe fora atribuída.

Um componente curricular com denominação inadequada poderá produzir uma formação acrítica, ou, segundo Zabalza (2007, p. 40), fazer com que o indivíduo aceite e se conforme com o planejamento de vida e de atividades para o qual foi formado ou conformado.

\section{Considerações finais}

$\mathrm{Na}$ pesquisa aqui apresentada, foi possível desvelarmos algumas características do componente curricular Física para os cursos superiores de tecnologia em construção de edifícios no período de criação e início de expansão desses cursos no Brasil.

Algumas lacunas foram preenchidas na literatura, principalmente em relação à origem da disciplina de Física para os cursos superiores de tecnologia, às suas finalidades prescritas na legislação, sua função enquanto conteúdo formativo e ao significado e contexto de uso para disciplinas de natureza aplicada.

268 DOI: Em andamento. 
Observamos que a ausência de conteúdos formativos relativos à Física Moderna e Contemporânea no currículo desses cursos, quer seja como conteúdo formativo cultural, quer como disciplinar geral e/ou específico, implica uma formação inadequada e deficiente. Essa ausência, por sua vez, aponta que o ensino de Física não desempenhava um papel principal no campo da Educação Básica para a formação do tecnólogo em construção de edifícios e que os profissionais formados estavam aptos para trabalhar no século XIX, mas não no período pesquisado, pois contrariava os objetivos postos para o componente curricular à época.

A inadequação na nomenclatura do componente curricular é o fator crucial, pois pode acarretar conformação no lugar de formação, tendo em vista que o conteúdo de instrução não estava a serviço da finalidade educativa prescrita, bem como correspondia a tópicos de ensino que não contemplavam uma adequada formação cultural e profissional para a vida societária do futuro profissional.

Consideramos que a presente pesquisa poderá trazer luz para estudos posteriores. Por se tratar de uma pesquisa histórica, documental e interpretativa, não tem por objetivo inferir conclusões, mas compreender e interpretar os processos. Acreditamos, assim, que é apenas o início de uma história que ainda está por ser escrita na História da Educação brasileira, uma vez que são necessários estudos específicos sobre cada Instituição de Ensino Superior que passou a ofertar esses cursos a partir de 1974, no processo de expansão dessa modalidade de cursos no país.

Por fim, acreditamos também que este trabalho auxilia na compreensão não somente da história da evolução da disciplina nos cursos, mas na apreensão do perfil do profissional do tecnólogo em construção de edifícios formado pelas Instituições de Ensino Superior do Brasil ao longo desses anos, podendo auxiliar tanto as instituições educativas no direcionamento das ações referentes à atualização permanente dos cursos e seus currículos quanto aos professores de Física para o pleno desenvolvimento de sua disciplina, além de contribuir com o debate sobre a formação profissional, particularmente no que tange aos conhecimentos de Física necessários para que esse tecnólogo possa atuar na aplicação, no desenvolvimento da pesquisa aplicada e da inovação tecnológica, na difusão de tecnologias, na gestão de processos de produção de bens e serviços, como é defendido no documento oficial.

\section{Referências}

ALVARENGA, Beatriz. Ciclo Básico e a Física. In: SIMPÓSIO NACIONAL DE ENSINO DE FísICA, 3., 1976, São Paulo. Mesas Redondas... Revista Brasileira de Física, volume especial, jul. 1976. São Paulo: Sociedade Brasileira de Física, 1976. v. 1, p. 217 - 219. 
ALVETTI, Marco Antonio Simas. Ensino de Física Moderna e Contemporânea e a Revista Ciência Hoje. 1999. 169 f. Dissertação (Mestrado em Educação) - Centro de Ciências da Educação, Universidade Federal de Santa Catarina, Florianópolis, 1999.

ANDRADE, Rodrigo Pinto de. História e Historiografia da Escola Luterana Concórdia de Marechal Cândido Rondon (1955 -1969). 2011. 265 f. (2 vol.). Dissertação (Mestrado em Educação) Universidade Estadual de Maringá, Maringá, 2011.

ARNAUT DE TOLEDO, Cézar de Alencar; GIMENEZ, José Carlos. Educação e Pesquisa: fontes e documentos. In: CASIMIRO, Ana Palmira Bittencourt S.; LOMBARDI, José Claudinei; MAGALHÃES, Lívia Diana Rocha (Org.). A pesquisa e a preservação de fontes e arquivos para a educação, cultura e memória. Campinas: Alínea, 2009. p. 109 -125.

BRANDÃO, Marisa. O Curso de Engenharia de Operação (anos 1960/ 1970) e sua relação histórica com a criação dos CEFETs. Revista Brasileira da Educação Profissional e Tecnológica. Brasília, Ministério da Educação, Secretaria de Educação Profissional e Tecnológica, v. 2, n. 2, p.55-77, nov. 2009.

BRASIL . Ministério da Educação. Conselho Nacional de Educação/Câmara de Educação Superior. Parecer no 29, de 03 de dezembro de 2002. Diretrizes Curriculares Nacionais Gerais para a Educação Profissional de Nível Tecnológico. Disponível em: <http://portal.mec.gov.br/cne/arquivos/pdf/cp29.pdf>. Acesso em: 23 set. 2012.

. Ministério da Educação. Conselho Nacional de Educação/Câmara de Educação Superior.

Parecer no 1.304, de 06 de novembro de 2001. Diretrizes Curriculares Nacionais para os Cursos de Física. Disponível em: <http://portal.mec.gov.br/cne/arquivos/pdf/CES1304.pdf >. Acesso em: 23 set. 2012.

. Lei no 4.024, de 20 de dezembro de 1961. Fixa as Diretrizes e Bases da Educação Nacional. Diário Oficial [da República Federativa do Brasil], Brasília, DF, 27 dez. 1961. Seção 1, p. 11429.

. Ministério da Educação e Cultura. Conselho Federal de Educação. Parecer no 280, de 17 de novembro de 1962. Currículo mínimo dos cursos de arquitetura e urbanismo. Documenta, Rio de Janeiro, n. 9, p.121-122, nov. 1962a.

. Ministério da Educação e Cultura. Conselho Federal de Educação. Parecer no 336, de 19 de outubro de 1962. Estabelece pela primeira vez os currículos mínimos dos cursos de engenharia no Brasil. Documenta, Rio de Janeiro, n. 9, p.134-137, nov. 1962b.

Ministério da Educação e Cultura. Conselho Federal de Educação. Parecer no 60, de fevereiro de 1963. Criação dos cursos de Engenharia de Operação - nova modalidade de curso de engenharia. Documenta, Rio de Janeiro, n. 12, p.51-53, mar. 1963.

270 DOI: Em andamento.

R. Bras. de Ensino de C\&T 
Portaria no 36, de 20 de dezembro de 1965. Fica homologado o currículo mínimo estabelecido para os cursos de engenheiro de operação, nas suas diversas modalidades. Diário Oficial [da República Federativa do Brasil], Brasília, DF, 17 fev. 1965. Seção 1, p. 1965.

. Decreto-Lei no 464, de 11 de fevereiro de 1969. Estabelece normas complementares à Lei no 5.540, de 28 de novembro de 1968, e dá outras providências. Disponível em: < http://www.planalto.gov.br/ccivil_03/decreto-lei/1965-1988/Del0464.htm>. Acesso em: 23 set. 2012.

- Ministério da Educação e Cultura. Conselho Federal de Educação. Departamento de Assuntos Universitários. Cursos superiores de tecnologia. Belo Horizonte: Mai Editora S. A., 1974. - Ministério da Educação e Cultura. Departamento de Assuntos Universitários. Estudos sobre a formação de tecnólogos. Brasília: MEC/DAU/UFMT, 1977.

BUFFA, Ester. História e filosofia das instituições escolares. In: ARAÚJO, José Carlos Sousa; GATTI JÚNIOR, Décio (org.). Novos temas em história da educação brasileira: instituições escolares e educação na imprensa. Campinas: Autores Associados; Uberlândia: EDUFU, 2002. - (Coleção memória da educação)

. O público e o privado como categoria de análise da educação. In: LOMBARDI, José C.; JACOMELI, Mara Regina M.; SILVA; Tânia Mara T. da (orgs.). O público e o privado na história da educação brasileira: concepções e práticas educativas. Campinas: Autores Associados; HISTEDBR; UNISAL, 2005. (Coleção Memória da educação). p. 41-58.

CHERVEL, André. História das disciplinas escolares: reflexões sobre um campo de pesquisa. In: Teoria e Educação, n.o 2, pp. 177-229. Porto Alegre: Pannônica, 1990.

COLL, César et al. Desenvolvimento psicológico e educação. Porto Alegre: Artmed, 2004.

COLL, César; SOLÉ, Isabel; ONRUBIA, Javier. Psicología de la Educación. Barcelona: EDIUOC, 1999. HEWITT, Paul G. Física Conceitual. 9. ed. Porto Alegre: Bookman, 2002.

LANÇA, Rui Miguel Madeira. Texto de apoio às aulas teóricas de Física Aplicada à Engenharia Civil. Faro: Universidade do Algarve, Escola Superior de Tecnologia, 2008. Mimeografado.

MARTí, José. Obras completas. La Habana: Editorial de Ciencias Sociales, 1976.

MOITA, M. C. Percursos de formação e de trans-formação. In: NÓVOA, A. Vida de professores. 2. ed. Porto: Porto Editora, 2000. p. 111-140.

MOTOYAMA, Shozo (coord.). Educação Técnica e Tecnológica em Questão: 25 anos do CEETEPS: uma história vivida. São Paulo: Editora da Universidade Estadual Paulista: CEETPS, 1995.

NÓVOA, A. Vida de professores. 2. ed. Porto: Porto Editora, 2000. 
OSTERMANN, Fernanda; RICCl, Trieste S. F. Relatividade restrita no ensino médio: contração de Lorentz-Fitzgerald e aparência visual de objetos relativísticos em livros didáticos de Física. Caderno Brasileiro de Ensino de Física, Florianópolis, v. 19, n. 2, p.176-190, ago. 2002.

PETEROSSI, Helena Gemignani. Educação e mercado de trabalho: análise crítica dos cursos de tecnologia. São Paulo: Edições Loyola, 1980.

RAMOS, Annita Guerra. O primeiro ciclo na universidade brasileira: contribuição para o estudo de sua implantação e funcionamento. 1979. 333 f. Dissertação (Mestrado em Educação) Departamento de Psicologia da Educação, Instituto de Estudos Avançados em Educação, Fundação Getúlio Vargas, Rio de Janeiro, 1979.

RIBEIRO, Márcio Willyans. Origens da disciplina de Geografia na Europa e seu desenvolvimento no Brasil. Diálogo Educacional, Curitiba, v. 11, n. 34, p.817-834, set.-dez. 2011.

RICARDO, Octávio Gaspar de Souza. Os Pioneiros: Octávio Gaspar de Souza Ricardo. São Paulo: 1995. Entrevista concedida a Shozo Motoyama e sua equipe, transcrita e publicada sob a forma de capítulo de livro. In: MOTOYAMA, Shozo (coord.). Educação Técnica e Tecnológica em Questão: 25 anos do CEETEPS: uma história vivida. São Paulo: Editora da Universidade Estadual Paulista, CEETPS, 1995. p. 111-130.

ROCHA, Manuel. A Física nas suas aplicações: A Física e a Engenharia Civil. Gazeta de Física, Lisboa, p. 24-31. out. 1946.

ROTHEN, José Carlos. Concepções de universidade na revista brasileira de estudos pedagógicos (1962-1968). Comunicações, Piracicaba, ano 12, n. 1, p.104-117, jun. 2005.

SÃO PAULO (Estado). Ato no 309, de 26 de novembro de 1968. Homologa a Resolução no 30-68. Diário Oficial [do] Estado de São Paulo, Poder Executivo, São Paulo, SP, 27 nov. 1968. Ano LXXVIII, no 226, p. 14.

. Decreto-Lei, de 6 de outubro de 1969. Cria, como entidade autárquica, o Centro Estadual de Educação Tecnológica de São Paulo, e dá providências correlatas. Diário Oficial [do] Estado de São Paulo, Poder Executivo, São Paulo, SP, 7 out. 1969. Ano LXXIX, no 191, p. 3.

SAVIANI, Nereide. Saber escolar, currículo e didática: problemas da unidade conteúdo/método no processo pedagógico. 6. ed. rev. São Paulo: Autores Associados, 2010.

SHULMAN, L. Those who understand: knowledge growth in teaching. Educational Research, v.2, n.15, p. 4-14, 1986.

SOARES, Vera. O ensino da Física no ciclo básico e a reforma universitária. Revista Brasileira de Ensino de Física, Sociedade Brasileira de Física, São Paulo, v. 1, n. 1, p.49-54, 1979.

SOCIEDADE BRASILEIRA DE FÍSICA. A física no Brasil. São Paulo: Sociedade Brasileira de Física, Instituto de Física da USP, 1987.

272 DOI: Em andamento.

R. Bras. de Ensino de C\&T 
TERRAZZAN, Eduardo Adolfo. Perspectivas para inserção da Física Moderna na escola média. 1994. 241f. Tese (Doutorado em Educação) - Faculdade de Educação, Universidade de São Paulo, São Paulo, 1994.

TOLLE, Paulo Ernesto. Os Pioneiros: Paulo Ernesto Tolle. São Paulo: 1995. Entrevista concedida a Shozo Motoyama e sua equipe, transcrita e publicada sob a forma de capítulo de livro. In: MOTOYAMA, Shozo (coord.). Educação Técnica e Tecnológica em Questão: 25 anos do CEETEPS: uma história vivida. São Paulo: Editora da Universidade Estadual Paulista, CEETPS, 1995. p. 99110.

VIANNA, Nelson Alves. O Tecnólogo e o Projeto 19. São Paulo: CEET-SP, ago. 1974. Palestra proferida pelo Dr. Nelson Alves Vianna, então diretor superintendente do CEET-SP, por ocasião da reunião do Departamento de Assuntos Universitários do MEC, em agosto de 1974. Transcrita por Shozo Motoyama e sua equipe e publicada sob a forma de capítulo de livro. In: MOTOYAMA, Shozo (coord.). Educação Técnica e Tecnológica em Questão: 25 anos do CEETEPS: uma história vivida. São Paulo: Editora da Universidade Estadual Paulista, CEETPS, 1995. p. 197-208.

WATANABE, Kazuo. Fase de Consolidação: Kazuo Watanabe. São Paulo: 1995. Entrevista concedida a Shozo Motoyama e sua equipe, transcrita e publicada sob a forma de capítulo de livro. In: MOTOYAMA, Shozo (coord.). Educação Técnica e Tecnológica em Questão: 25 anos do CEETEPS: uma história vivida. São Paulo: Editora da Universidade Estadual Paulista, CEETPS, 1995. p. 327-337.

YOUNG, Hugh D.; FREEDMAN, Roger A. Física I. 12. ed. São Paulo: Addison Wesley, 2008.

ZABALZA, Miguel Ángel. Competencias docentes del profesorado universitario: Calidad y desarrollo profesional. 2. ed. Madrid: Narcea, 2003.

. O ensino universitário: seu cenário e seus protagonistas. Porto Alegre: Artmed, 2007.

Fábio Aparecido da Costa - Mestre em Educação para a Ciência e a Matemática pelo Programa de Pós-Graduação em Educação para a Ciência e a Matemática (PCM) do Centro de Ciências Exatas (CCE) da Universidade Estadual de Maringá (UEM). Docente de Ensino de Física da Universidade Federal da Fronteira Sul (UFFS) - Campus Erechim. E-mail: fabio.costa@uffs.edu.br

Polônia Altoé Fusinato, Doutora em Educação e Mestre em Ensino de Fisica pela Universidade de São Paulo(USP) . Docente e Orientadora no Programa de Pós-Graduação em Educação para a Ciência e a Matemática (PCM) do Centro de Ciências Exatas (CCE) da Universidade Estadual de Maringá (UEM). E-mail: altoepoly@gmail.com 